\title{
LAS TIERRAS DE BALDÍO EN EL CONCEJO DE SORIA A FINES DE LA EDAD MEDIA
}

\begin{abstract}
SUMARIO
I. Las tierras de baldío en Soria. 1. El medio físico. 2. Las tierras de baldío. 3. Los términos y vocablos. - II. Del adehesamiento a la recuperación. 1. Dehesas y heredades. 2. Derechos y atribuciones en el uso de los baldíos. 3. La defensa de las tierras de baldíos - III. Los baldíos y el ganado trashumante en la tierra de Soria. 1. La situación económica a fines del siglo XV. 2. La madera. 3. La ganadería. - IV. Las tierras de baldío y el poder monárquico - Conclusión.
\end{abstract}

\section{LAS TIERRAS DE BALDÍO EN SORIA}

\section{Introducción}

Las tierras baldías o el baldío constituyen un apartado ineludible para todos los estudios que versen sobre economía medieval. Fuentes diversas ofrecen datos sobre estas tierras en toda Europa y figuran a modo de denominador común en la historia de la economía agropastoril europea. Pero su utilidad no es sólo económica; el uso de baldíos también contribuyó a reforzar la solidaridad de las gentes, cuando los usufructuaba en comunidad. Por último, se utilizaron como zonas de caza, al servicio de los grupos dominantes, que la practicaban como diversión y como adiestramiento '.

Las tierras baldías en la Península Ibérica llamaron la atención de diversos estudiosos, tal y como recoge Joaquin Costa ${ }^{2}$, si bien resaltaron en ellas su uso colectivo, que en la mayoría de los casos se remontaba al período medieval. Fue durante la reconquista y la repoblación cuando se demarcaron las tierras de baldío ${ }^{3}$ y

1 M.A. LADERO QUESADA, La caza en la legislación medieval castellana, «En la España Medieval», 1 (1980), pp. 193-222. 1973.

2 J. COSTA, Oligarquia y caciquismo. Colectivismo agrario y ofros escritos, Madrid, Nlianza Editorial,

3 Los historiadores del Derecho e institucionalistas han sido los que más se han interesado en su estudio: J. BENEYTO PÉREZ, Notas sobre el origen de los usos comunales, «Anuario de Historia del Derecho españolw, IX (19832), pp. 32-109. MARTíNEZ J. GIJÓN; A. GARCí UleCIA; B. CLAVERO SALVADOR, Bienes urbanos de aprovecbamiento comunal en los derecbos locales de Castilla y León, «Actas del II Symposium de Historia de la Administración, Madrid, 1974, pp. 539-550. 
durante el período bajomedieval se promulgaron ordenanzas diversas para su uso y conservación ". La Edad Moderna añade una documentación más precisa y los datos sobre la enajenación de estas tierras por parte de la monarquía '. Por lo general, el estudio de los baldíos se ha visto envuelto en polémicas hasta nuestros días y en la actualidad sigue siendo un tema histórico de estudio, que invita a la reflexión y a un análisis desapasionado ${ }^{6}$. La historiografía reciente ha seguido recabando a las fuentes nuevos datos sobre las tierras de baldío y en estudios monográficos se han recogido las particularidades de su uso '. No obstante, se empieza a hacer necesaria una reflexión sobre este tema ", a la cual contribuirá con éxito el presente número del "Anuario de estudios medievales".

En este trabajo el objetivo es seguir el curso de evolución de las tierras baldías en Soria, con perspectiva histórica y centrándolo en el período bajomedieval. Para ello el estudio del espacio geográfico es una referencia obligatoria, que aportará coordenadas precisas para la posterior valoración de los hechos históricos. Se podrá comprobar la particular importancia que este tipo de tierras tuvieron en la economía agropecuaria de Soria. Sobre ellas se fueron articulando distintos derechos, a resultas de una acomodación al influjo de los poderes, que se fueron concentrando en la zona, y a la jerarquía de los mismos. En este sentido el reinado de los Reyes Católicos se desvela como un período clave, en lo referente al reajuste de derechos que se produce en la zona, en favor de los ganaderos y muy particularmente del concejo de la Mesta.

\section{El medio físico}

El territorio del concejo de Soria se desenvuelve en el espacio interior del sistema

4 J.M. Mangas Navas, El nógimen comunal agrario de los concejos de Castilla, Madrid, Servicio de publicaciones agrarias, 1981. Única obra de conjunto reciente con valiosas aportaciones de gran mérito, si se tiene en cuenta que su autor es ingeniero agrónomo y un historiador autodidacta.

s D.E. VASSBERG, La venta de tierras baldias. El comunitarismo agrario y la Coroma de Castilla durante el siglo XVI, Madrid, Servicio de publicaciones agrarias, 1983.

6 R. ALTAMIRA Y CREVEA, Historia de la propiedad commmal, Madrid 1890. Reimpr. Madrid. Inst. de Est. de la Adm. Local. 1981. Como dice A. NIETO en el prólogo de la reimpresión: «En los últimos años del siglo XIX se manifiesta en España un inusitado interés por los estudios históricos de la propiedadx, pp. 13. Las obras de F. de CARDENAS, Ensayo sobre la bissoria de la propiedad servisorial en Espatia, Madrid, 1873. G. de AZCARATE, Ensayo sobre la bistoria dol derecbo de propiedad y su estado actual en Europa, Madrid, 3 vols. (1879, 1880 y 1883). La razón estriba en el protagonismo social y político que alcanza el propietario individual, a fines del siglo XIX, frente al sistema corporativo del período anterior. En estos autores se da la paradoja de una doble actitud: por un lado magnifican la propiedad individual, pero al mismo tiempo se percatan de que no es un factor constante y natural en la sociedad humana. ALTAMIRA mantuvo una postura heterodoxa, tanto respecto al Derecho positivo como a la historia y a la sociología. En este sentido se presenta como un hombre progresista, tal como afirma $\Lambda$. NIETO, pp. 14-15. Tanto R. ALTAMIRA como J. COSTA se sienten plenamente identificados con el «populismo agrarion, en una actitud idealista y falta de compromiso político.

En esta polémica, K. MARX y F. ENGELS defendieron la diferencia entre la propiedad comunal tradicional y el socialismo auténtico, afirmando que la disolución de la propiedad comunal en propiedad individual es una fase inevitable del proceso capitalista. (Ibid, pp. 18).

7 Cualquier intento de información bibliográfica sería desmesurado. Baste decir que la mayor parte de los trabajos, que versan sobre ciudades o señoríos urbanos y sobre señoríos laicos o eclesiásticos, contienen referencias a los baldíos.

- Es de lamentar que en la reciente obra de J.A. GARCÍ́ DE CORTAZAR, La sociedad nural en la Espanta Medieval, Madrid siglo XXI, 1988, no haya ningún apartado dedicado expresamente al estudio de los baldíos en la sociedad rural medieval. 
Ibérico y está volcado hacia el Duero ${ }^{9}$. El río es un elemento dominante en el espacio soriano y así se refleja en la toponimia como: Molinos de Duero, Miranda de Duero, Duruelo o Salduero, entre otros, sin olvidar que la ciudad se localiza a sus orillas. Desde su nacimiento por encima de los $2.000 \mathrm{~m}$, desciende bruscamente hasta el actual embalse de la Cuerda del Pozo a 1.100. A partir de ahí entra en una zona llana, en sentido hacia el Este: es el pasillo intramontañoso, marcado por la ruta natural Burgos-Soria, hasta la curva de Numancia. A partir de aquí el río continúa en dirección Sur, por el tramo de los Altos Campos horizontales, compartimentados por pequeñas sierras; éstas al ser horadadas por el río dan lugar al paisaje característico de la ciudad de Soria, a una altitud de $1.000 \mathrm{~m}$. Desde aquí el descenso hasta Almazán $(938 \mathrm{~m})$ lo hace en una pendiente algo mayor y a través de una vegetación espesa, entre bosques naturales ${ }^{10}$.

Soria se extiende a lo largo de un terreno sedimentario, cerrado en los extremos por los tres ramales del Sistema Ibérico (Noroeste, Este y Sur). Esos sedimentos silíceos, en la Sierra de la Demanda y el Moncayo, y calcáreos en el resto fueron modelados por la orogenia alpina y más tarde por la erosión. La mayor parte del territorio del concejo de Soria tiene una altitud superior a los $1.000 \mathrm{~m}$ y sólo en los llanos de Gómara al Sudeste desciende ligeramente. Las temperaturas son frías. En la actualidad Soria es la ciudad más fría de España en octubre, abril y mayo, y la azotan fuertes vientos. Junto a la altitud y al frío se puede citar algún otro factor, como la mala calidad del suelo, en la casi total extensión de la tierra. Así, se llega a la idea del determinismo físico para explicar las bajas cifras demográficas que tiene Soria en la actualidad".

En el presente trabajo se busca una explicación a ese problema de la despoblación, a través del estudio de la ocupación y explotación de esas tierras de mala calidad, bajo unas temperaturas extremas y frías. Tales circunstancias sólo son compatibles con una agricultura de secano, volcada en el trigo, y combinada con la ganadería. La adaptación a la dureza del medio se lograría gracias a la movilidad física de los grupos humanos, en la tierra de Soria, y también a una fuerte cohesión social. Esa cohesión se apoyaría firmemente en los lazos de parentesco y, a partir del siglo XIII, se iría estableciendo sobre las relaciones de dependencia, en el marco de una sociedad feudal ${ }^{12}$, en la cual se mantenía en el período estudiado, convertida en estructura social dominante, si bien ello no supuso que hubiese habido sustitución de unas formas sociales por otras. Se habría producido una coexistencia de ambas formas de solidaridad, pero las de carácter feudal dominarían al marcar las pautas de la movilidad social, y del acceso al poder y a la riqueza.

9 J.M. PALA BASTARÁS (Dir.), Análisis del medio fisico de Soria. Delimitación de mnidades y estructura serritorial, Valladolid, Edit. EPISA, 1988. La consulta de este trabajo ha sido fundamental. M. de TERAS y L. SOLÉ SABARfS y otros, Goografía negional de España, Barcelona, Ariel, 1969, pp. 100-154.

10 J.M. PAla BastarÁs (Dir.), op. cit., p. 16.

11 Ibid. pp. 24. Con un criterio más abierto los autores de este trabajo no aceptan la idea del determinismo físico y creen que factores históricos son los que tienen que explicar la despoblación soriana.

12 La elocuencia de los documentos del siglo XIII avala estos argumentos: G. SÁNCHEZ, Fueros castellanos de Soria y Alcalá de Henanes, Madrid, 1919. E. JIMÉNO, La pobleción de Soria y su tónmino en 1270, «Boletín de la Real Academia de la Historiaw, 142 (1958), pp. 207-274, 365-494. 


\section{Las tierras de baldio}

En castellano el término baldío, aplicado a terrenos, significa yermo o estéril ${ }^{13}$. No obstante, su significado permitía matices sobre la utilización que se daba a esas tierras ${ }^{14}$. Para Soria la reflexión sobre baldíos nos lleva a la repoblación cristiana del territorio. Con anterioridad esas tierras podían haber estado vacías y casi desiertas ${ }^{15}$. Lo cierto es que a partir del siglo XI se mencionan algunos topónimos y, si el límite en 1088 llegaba a Calatañazor, a partir de 1136 se extendía hasta Urbión para la diócesis de Osma ${ }^{16}$. La ocupación del extenso espacio que abarcaba la tierra de Soria se hizo a partir de los baldíos existentes, pero en este caso el sistema de presura que, según recogen los fueros, garantizaba el derecho de usar tierras desiertas y no labradas, no podía llegar a perfeccionarse por la ocupación prolongada de la tierra. La razón estribaba en la deficiente calidad del suelo y las difíciles condiciones climáticas, unidas a la escasez de medios y técnicas para desarrollar una agricultura sedentaria. En esas condiciones la ganadería sería el medio de vida predominante que se vería complementado con una agricultura de subsistencia, basada en la quema y roza de los áridos terrenos.

La actividad ganadera predominante y la mala calidad de los terrenos habrían obligado a la población a desplazarse de unos lugares a otros, a medida que la productividad de los suelos se iba agotando. De esta manera la despoblación de algunas aldeas era algo inevitable y, para compensarlo, contaban con la gran extensión del territorio demarcado para Soria de unos $2.998,21 \mathrm{Km}^{2}$, donde se localizan 168 aldeas y 155 despoblados ${ }^{17}$. Estas difíciles condiciones tuvieron que retrasar la aparición de propiedad solar, si entendemos ésta por tierras de cultivo permanente. Resulta más probable que fuese al adehesamiento la fórmula que contribuyó a estabilizar a la población. Con el tiempo se añadirían el cultivo de la vid y la explotación maderera, con vistas a la comercialización.

La escasez de fuentes para la historia de Soria en la Plena Edad Media se compensa, en gran medida, con la conservación del fuero extenso otorgado por Alfonso X en 1256. Durante siglos el fuero siguió conservando vigencia y a fines del siglo XV se utilizaba como referencia indiscutible para solucionar asuntos internos. En el fuero se contenían disposiciones para regular las formas de ocupación y explotación del suelo. Esas normas debieron ser interpretadas, traduciendo el propósito de Alfonso X que trataba de contribuir, por todos los medios, a la sedentariza-

13 M. MOLINER, Diccionario de uso del esparnol, Madrid, Gredos, 1980, vol I, pp. 334. Procede del latín evalidus y se aplica para «la tierra que no se labra ni está adehesadaw. Ver M. ALONSO, Diccionario Medieval Espantol. Desde las Glosas Emilianenses y Silenses (S.X) basta el siglo XV, Salamanca, Universidad Pontificia de Salamanca, 1986, p. 484

14 D.E. VASSBERG ha zanjado este problema aceptando que para el siglo XVI «tierras baldías* y *baldíos* se aplican a aquellas tierras realengas no concedidas por la Corona y en consecuencia disponibles al aprovechamiento público. «La venta de tierras baldías... op. cit., p. 30.

15 G. MARTÍNEZ DíEZ, Las comunidades de villa y tierra, p. 148. Según las crónicas musulmanas en el año 920 la región soriana constituía un extenso desierto.

16 Ibid. p. 156.

17 G. MARTíNEZ DÍEZ, op. cit., p. 182. 
ción de la población, tanto en la ciudad como en la tierra ${ }^{18}$. El primer título del fuero regulaba la utilización de montes y término. Las disposiciones buscaban la protección frente a extraños, permitían a los vecinos labrar los exidos y cazar, siempre que no lo hiciesen con rapaces o con perros, debido a que esa práctica se reservaba a nobles y caballeros. También podían cortar madera y hacer carbón, si no era para sacarlo fuera del término ${ }^{19}$.

Para evitar un uso abusivo de los montes se limitaban las talas y la recolección a satisfacer la necesidad cotidiana y fijaban la época, bajo penas de montazgo ${ }^{20}$. La articulación entre productos de recolección y calendario pone el énfasis en favorecer el aprovisionamiento inmediato y evitar la acumulación excesiva o la comercialización.

Entre los posibles usos del monte se incluye como una posibilidad más la de rozar o roturar la tierra, que se podía hacer siempre y cuando fuesen terrenos de su propiedad (heredad) o en los exidos secos del término ${ }^{21}$. El objetivo de esta limitación es preservar las tierras de pasto y el bosque de una agricultura de quema, a la búsqueda de suelos fértiles. En aquellas situaciones no previstas en el fuero se precisaba de la intervención regia, como la otorgada por Pedro I a los vecinos de Posada del Rey, aldea de Soria en el límite con la Merindad de Logroño y la comunidad de Yanguas ${ }^{22}$. Desde fines del siglo XV la demanda de tierras para labrar se hace más fuerte en los concejos del Norte, sobre todo en la zona de Pinares. En las reclamaciones presentadas figuran los concejos de Vinuesa, Covaleda, Salduero, Derroñadas, El Royo, Noviercas, Herreros, Vilviestre, Angosto, Valdeavellano, Sotillo del Rincón, Villar del Ala, Aldehuela, Adovezo, Rebollar, Rollamienta, San Andrés de Almarza, La Poveda, Arguijo y Duruelo ${ }^{23}$.

18 M. ASENJO GONZÁLEZ, Fiscalidad negia y sociedad en los concejos de la Extremadura castellano-oriental durante el reimado de Affonso X, «Homenaje al Profesor Juan Torres Fontes», Murcia, Univ. de Murcia, 1987, 1, pp. 69-84.

19 G. SÁNCHEZ, Op. cit., I, 2: «Si omne estranno que non sea vezino labrase en los exidos, pierda los bueyes e las bestias con que labrare...n, 3: «El que caçare con aves o con canes peche dos mrs. e pierda la caza, salvo si fuere ric omne o otro cavallero de passada. Et essa misma calonna peche el que caçare con redes o con ballesta o con otro enganno qual quiere, o si fuere fallado pescandow, pp. 8-9: Todas las razones se dan en función de extraños, no de los vecinos. El título II trata de «La guarda de los montes e del termino contra los vecinos», pp. 10-15.

20 El término montazgo abarca cualquier sanción por el uso indebido de los baldíos. Un ejemplo de pautas para la recolección, II, 11: «Los çenllos sean quitos de coger desde el primer día de setiembre fasta tres semanas de pues de San Miguel. Trillos e forcas e palas, desde el dia de Sant Juhan fasta el dia de Sancta Maria mediado agoston. Posiblemente genllos daría lugar a ncenejan: tejido de esparto (Murcia).

21 Ibid. pp. 13, I, 19: «Aquel que roçare en su heredat, non sea montado por ello, nin por roçar seco en los exidos del termino; e si roçare verde en los exidos del termino, peche $\mathrm{V}$ mencalesw.

22 Arch. Mun. de Soria. (s.l.) 6 Mayo 1354. La localización fronteriza de esta aldea podría justificar la excepción.

23 ARChivo General de SimanCAS/REgistro GenerAl DEL SELlO. En adelante AGS/RGS, XI1483 f. ${ }^{\circ}$ 64: «desiendo quellos e cada ono dellos de tiempo ynmemorial a esta parte que memoria de ombres non es en contrario han estado en posesión paçifica de paçer e roçar en los terminos e montes desa dicha çibdad e de faser en ellos çerrados en que siembran e cogen pan para sus mantenimientos pagando vos ellos en cada un año un çenso o tributo...»; AGS/RGS, X-1498, f. ${ }^{\circ}$ 82; Ibid. 17-X-1 504: el concejo de Duruelo reclama autorización para labrar 12 leguas o más, que habían venido labrando durante más de 60 o 70 anos y que ahora el concejo de Soria se lo impide; AGS/RGS, VIII-1510. Los concejos de La Poveda, Arguijo, Valdeavellano, Salduero y Herreros dicen: «al tiempo que los dichos logares se empeçaron a poblar les dieron algunos termino en que sembrasen segund el numero de vesinos que a la sazon abia en cada lugar, e dis que despues aca se an aumentado e pobladox, de tal forma que solo disponen de un tercio de las tierras que necesitan: AGS/CONSEJO REAL Leg. 72-16 año 1504. 
A fines del siglo XV ya se había construido una jerarquía de poderes que controlaba los baldíos. En este período de tiempo, las condiciones económicas de estos lugares mencionados de la sierra se habrían visto mejoradas gracias a la explotación maderera, la población habría aumentado y de ahí su necesidad de tierras.

\section{Los términos y vocablos}

El lenguaje utilizado para referirse a la tierra, en sus diversas formas de ocupación, puede aclarar algunos aspectos acerca de la situación de la misma. El término baldíos no aparece en la documentación y para designar a las tierras incultas se utilizan monte y exidos. También se les denomina comunes, concejiles y realengos, términos que definen su situación jurídica. Si las tierras están ocupadas se utilizan: debesas y beredades o bien términos redondos, términos apartados y términos derraygados. $\mathrm{El}$ análisis de estos nombres puede ayudar a comprender las formas de organización del espacio y de la vida socioeconómica en la tierra de Soria.

En el fuero de Soria los baldíos aparecen como monte y cuando se utiliza término se refiere a la propia demarcación del territorio de la tierra ${ }^{24}$. La documentación ofrece otros ejemplos en los que término indica la demarcación que corresponde a cada lugar poblado para su uso ${ }^{25}$. Ese espacio se entregaba al asentar una puebla y se iba aumentando a medida que las necesidades lo requerían. Todo debía de hacerse bajo el control del concejo, según disponía el fuero ${ }^{26}$. Las demarcaciones entregadas se denominaban pagos y se destinaban a la labranza o al adehesamiento.

En la documentación se recoge el caso de La Poveda, solucionado a partir de la intervención regia, tras la reclamación de los vecinos de este lugar y ante la negativa del concejo a conceder las tierras. A los vecinos se les otorgan dos pagos: uno en el lugar del Adovezo y otro en el camino de Posada del Rey ${ }^{27}$. Los criterios propuestos en el documento acerca de la explotación de la tierra resultan de gran interés.

Sabemos muy poco acerca de como se planificaban los cultivos. La quema y roza de los campos exigía movilidad para las gentes que vivían en ella, pero desde la segunda mitad del siglo XIII esa movilidad se iba haciendo más difícil. Por una parte los asentamientos y la aparición de dehesas y heredades había acabado con la posibilidad de utilizar las tierras más aptas o las que estuvieran mejor emplazadas, y vecinosw.

24 G. SÁNCHEZ, El fuero de Soria, op. cit., II, «Capítulo de la guarda de los montes e del termino contra los

25 AGS/RGS, IV-1503, Alcalá de Henares. Comisión al concejo de Soria para que señale cierto término al concejo de La Poveda. Tras la negativa del concejo de Soria a concederles término, se hizo pesquisa y se supo que efectivamente el lugar de La Poveda tenía necesidad de tierras para labrar.

26 Ibid.: II-26: «Pueblas que de nuevo fueren fechas en el termino del conçejo non queriendo, non sean estables, e destruyanlas sin calonna ningunax.

27 Ibid.; a...que buenamente se les podia dar para ello un pedaço de un tormino que esta fasia el logar del Adobeço y por Osvanda y al camino de Posada del Rey para un ańo y para otro año otro tormino desde el dicho camino de Posada Rey fasya el Oynello de exido e al do fasta el termino de Arguijo y que en un año se labrase el un pago e el otro año el otro, y que el pago que el an̂o toviese sembrado lo podiesen sembrar, para que estoviese guardado, y que algado el pan se aportillase el dicho serrado y quedase por pasto común para todos como agora lo es. Fue racordado que deviamos mandar dar esta nuestra carta en la dicha rason.... 
a esto había que añadir las disposiciones del fuero, que imponían limitaciones y el control del concejo sobre esos asuntos. La paulatina tendencia a la sedentarización obligaba a los hombres a sacar el mejor partido de las tierras de su entorno, sin agotar el suelo y haciéndolo compatible con las exigencias de pastos que planteaba el concejo de Soria. El sistema de año y vez es el propuesto en el documento, pero no organizándolo en hojas, sino cultivando alternativamente: un año un pago y al año siguiente el otro ${ }^{28}$.

Así, el concejo se beneficiaría por partida doble: primero porque los ganados llevados allí se beneficiarían de la derrota de mieses y además porque percibían una cantidad en concepto de renta de la tierra, pagada por los vecinos ocupantes ${ }^{29}$. A pesar de estas compensaciones el concejo de Soria se mostraba reticente a efectuar esas concesiones de términos, y fue gracias a la intervención regia como los vecinos de Salduero recibieron las tierras, encargándole al corregidor la supervisión ${ }^{30}$.

Así, los términos figuran como tierras asignadas, a las que se puede dar un uso agrícola o ganadero ". La acotación que se efectuaba sobre esas tierras las equiparaba a las dehesas o a las heredades, si bien los términos eran espacios de uso colectivo. Esta explicación resulta básica si queremos entender lo que significan términos redondos y términos derraygados.

Términos redondos son aquellos que permanecen bajo el poder de un señor y surgen al hacer acotaciones en un territorio hasta cerrarlo. Tales términos podrían haber sido poblados y explotados bajo la tutela del señor, el cual los habría adquirido por concesión del concejo o por usurpación. De su existencia han quedado noticias a través de pleitos ${ }^{32}$, que prueban que en su mayor parte estaban en manos de los miembros de la oligarquía urbana ${ }^{33}$. La diferencia entre un término concejil y un término redondo es que en este último no se practicaba la derrota de mieses ${ }^{34}$, de esta manera se ponía de manifiesto su condición de tierras de señores y caballeros, según expresa un documento de $1507^{33}$. La existencia de estos términos plantea interro-

2a J. GARCÍA FERNÁNDEZ, Campas abiertas y campos cencados en Castilla la Vieja, aHomenaje al Exmo. Sr. D. Amando Melón», Zaragoza, 1966, p. 123. Este autor planteó con agudeza el problema del desconocimiento de cuando se va utilizando el sistema de hojes. Él opinaba que no era anterior al siglo XVI en muchos lugares.

29 AGS/RGS, IV-1 503, doc. cit.: «asi lo mandan que se haga mientras lo necesiten y disponen que mientras lo tengan cultivado lo puedan cerrar con una pared y que recogido el fruto se levante la paredw, para que pueda entrar el ganado de todos los vecinos de la dicha ciudad. Manda que los vecinos del dicho lugar den en renta, cada año, por cada fanega de pan y de otras semillas lo que ellos piensen que deben pedir y que quede como propios de la dicha ciudad.

30 Ibid.: IV-1497, fol. 74, Burgos 15 de abril de 1497.

31 AGS/RGS, VI-1485, fol. 148.

32 ARCHIVO HISTÓRICO NACIONAL/MESTA (En adelante AHN/MESTA). Caja 193 (11): Sentencias dadas en facor del concejo de la Mesta por el licenciado Chinchilla. 1514.

33 ARChivo de la ReAl Chancillerf́a de VAlladolid/EjeCutorias Reales. (En adelante: ARCHV/ER) Leg. 2. Ejecutoria dada a favor de Gonzalo de Molina, vecino de Soria, contra María de Vera de la misma ciudad sobre el término redondo, llamado de Vergela, con sus casas, tierras y demás del concejo, sito en el término de la dicha ciudad. Junio 1486; AGS/RGS, IV-1501. En Valladolid a 19 abril 1501, el monasterio de Valvanera hace una reclamación de un término redondo en Fuentetova, próximo a la ciudad de Soria, que sin duda le habrian sido legado por su anterior propietario.

34 J. GARCIA FERNÁNDEZ, Campas abiortos... op. cit., pp. 709- 715.

33 AGS/RGS, III-1507, Palencia 19 marzo 1507. Los procuradores de la Universidad de la tierra de Soria dicen: «que en la dicha tierra desa dicha çibdad esta en comarca de muchos señores e caballeros que tienen logares e 
gantes de difícil respuesta, al mismo tiempo que pone de manifiesto que el espacio es un testigo importante, con el que se debe contar a la hora de valorar procesos históricos.

Los términos derraygados se constituyen a partir de las tierras de pasto y de labor de los lugares despoblados ${ }^{36}$. En teoría estos términos al quedar abandonados pasaban a ser de realengo, pero los procuradores de la tierra de Soria se quejaban en 1507 de que el concejo los entrega a personas extranjeras que, con el pretexto de ocuparlas y poblarlas, llevaban sus ganados y, en el período que les daban para que se avecinasen (de seis meses a un año), aprovechaban para beneficiarse de los pastos del lugar ${ }^{37}$. Se les estaba dando un uso equivalente al de propios concejiles.

El análisis de la terminología y vocablos utilizados para denominar a las tierras han servido de argumento para comprender cuales han sido las vías de ocupación y asentamiento. Debido a que los espacios baldíos del término de Soria se habían ido desbrozando y ocupando, en condiciones difíciles y con escasos medios, la adaptación a los sucesivos cambios sociales, políticos, económicos e institucionales tuvo que influir en la particular configuración del espacio soriano, tendiendo a hacer a su población más sedentaria, al tiempo que se adaptaba a las formas feudales de dominación social y económica. En el espacio se fue dejando huella de esas adaptaciones que al filo del siglo XVI serán aún más convulsivas.

\section{DEL ADEHESAMIENTO A LA RECUPERACIÓN DE LOS BALDÍOS}

\section{Debesas $y$ beredades}

Los términos debesas y beredades tienen en común su condición de territorios acotados. En el período de asentamiento la aparición de estas formas particularizadas de ocupación tuvo que ser frecuente; las formas de presura contribuirían en buena medida a ello, tal y como se ha señalado.

A fines del siglo XV la adquisición de una heredad sólo se podía alcanzar por compra, donación o por reparto, con la aprobación del monarca y el plácet del concejo ${ }^{38}$. La aparición de nuevas heredades era difícil y la vía mas rápida para adquirirlas era la compra. Los caballeros eran los más interesados en adquirir tierras de labor en propiedad, que no se buscaban precisamente con el propósito de ponerlas en cultivo. En efecto, estas tierras se utilizaban como argumento para poder tener acceso a los pastos del concejo al que pertenecían. Así se expresa en un documento de la reina Juana, otorgado al concejo de Noviercas en 1505, para impedir que personas

\footnotetext{
serminos apartados e que hasimismo otros los tienen dentro de la dicha tierra e termino desa dicha çibdad, e diz que cuando algunas personas o ganados toman en sus terminos e llevan muchas penas ynmoderadas...».

36 AHN/MESTA, Caja 193 (11), doc. cit. fol. 16v: «Otrosy se prueba que en tierra de la dicha çibdad de Soria ay otros terminos que llaman raygados de lugares que antiguamente fueron poblados y estan agora despoblados los quales son avidos por terminos realengos exçeto si alguno probare tener heredad propia en ellosw.

37 AGS/RGS, III-1507, Palencia 19 de marzo 1507.

38 AGS/C-C (Pueblos), Leg. 20, Madrid 25 enero 1514. Se solicita de S.A. licencia para repartir heredades en la tierra de Soria, ya que la población habla crecido.
} 
principales comprasen heredamientos y con ellos los derechos de pastos concejiles. Esa prohibición se quiere hacer extensiva a la ciudad de Soria y a su tierra ${ }^{39}$.

Las dehesas son también espacios acotados, destinados al uso pecuario. Cualquier adehesamiento precisaba contar con autorización, ya que se consideraba que las dehesas mermaban la extensión de los pastos comunales, que debían ser usufructuados por todos. En el siglo XIII, el fuero limitaba la creación de dehesas, aduciendo estas razones ${ }^{40}$, pero el control de las dehesas buscaba también el asentamiento de la población. No olvidemos que estas tierras podían poseerse en lugares diferentes y mover los ganados con facilidad, contando con ellas. Las dehesas podían ser particulares y comunales, y es posible que el fuero tratase de frenar la creación de dehesas particulares, no así de las comunales, que se siguieron creando durante toda la Edad Media.

\section{A. Las dehesas comunales}

Sabemos que las dehesas comunales eran numerosas en la tierra de Soria. La misma ciudad contaba en su proximidad con un gran territorio adehesado, llamado Valonsadero, que se extendía en dirección noroeste, abarcando zonas de arbolado (encinas, robles, carrascas) y de paso ${ }^{4}$. Debido a su tamaño funcionaba como un enorme terreno baldío acotado y defendido a los extraños ${ }^{42}$.

Aunque las dehesas comunales se relacionan con la explotación ganadera, en algunas ocasiones podían ser cultivadas por los vecinos del lugar. Eso es lo que ocurre en la de Valonsadero en 1475, 1495 y 1497, fechas en las que se repartió la tierra, «a partes iguales» entre los vecinos, para que la labrasen ${ }^{43}$. En 1497 , a pesar de la oposición de la oligarquía urbana la monarquía autorizó la siembra de la dehesa de Valonsadero y en las disposiciones que la regulaban se buscaba lograr un reparto equitativo entre los vecinos, sin perjudicar a la oligarquía. Se preservaron las tierras de pasto y se garantizó el acceso de sus ganados a la derrota de mieses ${ }^{44}$.

Estas dehesas comunales eran zonas de explotación y de dominio vinculadas a

39 AGS/C-C (Pueblos) Leg. 20, Toro 28 febrero 1505: «Los caballeros e personas prinçipales...e han comprado en ella (Soria) y en sus tierras e heredamientos lugares e terminos, que so color de lo que así compran meten a ervajar sus ganados en los terminos de los dichos lugares donde han comprado los dichos heredamientos. E se despueblan en los lugares a ellos comarcanos estan para se perder.... . Solicitan de la monarquía una provisión real que impida a personas principales y caballeros adquirir esas heredades, bajo amenaza de perder los bienes comprados y lo pagado por ellos.

40 G. SÁNCHEZ: Fuero de Soria... op. cit.; IV-36: «Si algunas aldeas an dehesas de pasto por cartas de los reyes o las ovieren daquí adelant, alli do el rey les quisiere fazer merçed, que las ayan; e los deheseros que coian la calonna de los dannadores... En otra manera ninguna non pueda fazer dehesa de pasto, maguer las heredades o el termino en que las quisieren fazer fuere suyo, ca los pastos comunales deven ser a todos los vezinos de Soria e de su terminow.

41 Ibid. III-27-33. Pp. 15-16: «Capítulo dela guarda de Val-ffonssadero».

42 Así se presenta la dehesa de Valonsadero, cuya defensa se organiza como si de un término baldío se tratase. Ibid. pp. 15-16.

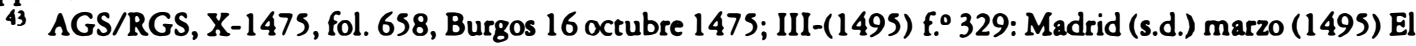
reparto de la dehesa dio lugar a alborotos en la ciudad, entre los vecinos; I-1498, fol. 99, Madrid 20 enero 1498; IV-1498; IV-1497 fol. 29, Burgos 24 abril 1497; XII-1497, fol. 107, Madrid 23 diciembre 1497.

44 AGS/RGS; IV-1497. 
los concejos. De tal forma que, mientras los baldíos o montes eran espacios abiertos de uso común a los vecinos de la ciudad y de la tierra, los términos concejiles, por razón de uso y de proximidad, quedaban más vinculados a alguna aldea o lugar. Por último, las dehesas comunales representaban espacios acotados y de uso restringido. El paso de un término común a dehesa comunal pudo ser la forma más extendida de su aparición, contando siempre con la aprobación del concejo de Soria ".

$\mathrm{A}$ fines del siglo $\mathrm{XV}$ las dehesas comunales debieron de conocer presiones y amenazas, como indica la reclamación del concejo de Tardajos ${ }^{40}$. Lo cual nos indica las dificultades que encontraron aquellos concejos, que quisieron que sus términos concejiles fuesen reconocidos como dehesas. En 1497 se envió una provisión real al corregidor de Soria para que, junto con dos regidores y los procuradores de la ciudad y de la tierra, determinasen qué dehesas eran necesarias en algunos lugares ".

La razón de tantos impedimentos está relacionada con la necesidad de pastos para el ganado lanar, que se estaba desarrollando con fuerza en la tierra soriana. Aquellas aldeas o lugares que no hubiesen acotado sus tierras concejiles de pasto y de labranza iban a encontrar serias dificultades en hacerlo a partir de ahora. El concejo no favoreció expresamente a los lugares y aldeas de su tierra, en este asunto, y en ocasiones pidió a S.S.A.A. que anularan alguna decisión tomada en este sentido. Como ocurrió en 1492, cuando la ciudad de Soria pidió que se revocara la merced de cierta dehesa, hecha por sus altezas al lugar de Quintana Redonda por cuanto iba en perjuicio de los demás concejos de la tierra y de la dicha ciudad ${ }^{48}$. La reclamación del concejo no debió surtir efecto porque los monarcas dispusieron como guardar la dicha dehesa y encargaron a Ruy Díaz de Mendoza, tío del Conde de Monteagudo y contino de sus altezas, que pusiera a los guardas de entre los vecinos del lugar y que repartiese las penas a partes iguales, entre los guardas y la iglesia de Quintana Redonda ${ }^{4}$. Como se verá más tarde, la defensa del beneficio común en el argumento de los regidores estaba encubriendo un uso bien distinto para esas tierras concejiles.

\section{B. Las dehesas privadas}

El adehesamiento realizado por particulares nos resulta peor conocido, en el caso de Soria. Sólo las reclamaciones o denuncias ponían de manifiesto esas situaciones, que se presentaban como anómalas. Las leyes sobre devolución de términos ocupados, aprobadas en las Cortes de Toledo de 1480, permitieron a «los hombres buenos de la Universidad de la tierra de Soria» emplazar a ciertas personas que habían hecho

4s AGS/C.-R., Leg. 72-16, fol. 9r: El concejo de Duruelo, tierra de Soria, apela ante S.A. y dice: «...que la dicha çibdad tiene doze leguas e mas e de terminos comunes e conçejiles e mucha parte dellos se acostumbra a labrar para y por los vesinos e moradores de los otros lugares de la tierra de la dicha çibdad e espeçialmente por los vesinos e moradores del dicho lugar de Duruelo... diz que labraron estas tierras desde tiempo inmemorial.....

46 AGS/RGS, V-1486, fol. 19, Valladolid 6 mayo 1486. Carta de amparo al concejo de Tardajos en la utilización de unos prados que especifica.

47 Ibid. IV-1497, fol. 124, Burgos 15 abril 1497.

48 Ibid. VIII-1492, fol. 1.

49 AGS/RGS, II-1492, Santa Fe 25 febrero 1492. 
dehesas recientemente ${ }^{\text {so }}$. En la alegación presentada se mencionan los nombres de caballeros, hidalgos y hasta del alcaide de la fortaleza de Soria. La causa de estos adehesamientos dicen que fue el desconcierto y la confusión que reinó en vida del rey Enrique IV, alegan también que cuando se les ha pedido que lo desocupen no han querido hacerlo, «por ser personas muy emparentadas en la dicha çibdad, e ricos, e allegados a personas poderosas de la comarca».

La aparición de estas dehesas particulares no parece que se relacione con el acotamiento de terrenos frente a la expansión de la ganadería lanar, sino que tendría que ver con el afán de tierras y poder de una oligarquía urbana acosada por los poderes señoriales y dividida.

A modo de conclusión cabe añadir que se comprende la preferencia de los vecinos de la ciudad o de la tierra por las dehesas, porque a todos los efectos eran en Soria demarcaciones mejor protegidas que las heredades. Sólo las dehesas quedaban a salvo de la entrada de ganados, mientras las heredades pasaban a ser pastos comunes, en cuanto dejaban de estar sembradas, lo cual las convertía en territorios difíciles de mantener en cultivo a fines del siglo XV, dada la presión de los ganaderos.

\section{Derechos y atribuciones en el uso de los baldios}

A lo largo de estas páginas se ha ido significando la importancia que el uso de los baldíos tenía en la vida económica soriana. Esas tierras no se utilizaban como complemento a una actividad agraria dominante, sino que constituían la base del sistema económico de Soria y de su tierra. Unas tierras de baldío que se cultivaban, se utilizaban para pastos y permitían la recolección, la caza, la pesca y la corta de madera. En cualquier caso, la tierra difícilmente perdía su condición de común y concejil y sólo el adehesamiento podía acabar con ella. Pero sobre estos suelos versátiles, a causa de su pobreza, se fueron definiendo distintos poderes, que en ocasiones se solaparon o entraron en colisión.

Ateniéndonos a la organización administrativa y de gobierno del Concejo de Soria, con intereses en el uso de las tierras comunes, distinguimos a estos titulares: el monarca o el señor jurisdiccional, el regimiento, la comunidad de hombres buenos de la ciudad de Soria, la universidad de hombres buenos de la tierra, el concejo del lugar o aldea, y por último los vecinos moradores, que estaban autorizados por la costumbre y el fuero para usar esas tierras.

El máximo poder sobre los baldíos lo ejercía la monarquía. Pero desde la concesión del fuero en 1256 los reyes no volvieron a decidir en la organización y el gobierno de las tierras comunes, salvo para intervenir en asuntos puntuales, a instancia de parte. Durante ese largo período el poder de gobierno y administración de términos comunes correspondía al concejo, cuya capacidad de acción se limitaba, a su vez, a la aplicación de las disposiciones del fuero sobre la utilización de esas tierras, atendiendo a: la preservación del territorio y de su población, su sedentariza-

so AGS/RGS, III-1480, Toledo 23 marzo 1480, fol. 225. La mayor parte de los mencionados son caballeros e hidalgos de la ciudad, el propio alcaide de la fortaleza de Soria Gonzalo de Betera. 
ción progresiva y la ampliación de los patrimonios de sus miembros, sin que ello pusiera en peligro el equilibrio colectivo custodiado por los doce linajes en los que se agrupaba la oligarquía urbana de los caballeros de Soria.

De esta manera el concejo de Soria ejercía un poder equiparado al de un señorío colectivo en su tierra y gobernaba los llamados términos concejiles o términos comunes, que seguían siendo a fines del siglo XV la mayor parte del territorio. La identidad entre términos concejiles y términos realengos parece segura, pero un documento de 1510 trata de diferenciarlos, al exponer la necesidad que tienen de nuevos términos en los lugares de La Poveda, Arguijo, Valdeavellano, Salguero y Herreros, donde dice que ha aumentado la población de tal forma que tienen *...términos para sembrar el tercio de lo que an menester e que a esta cabsa rompen e haran en los términos realengos desa dicha çibdad e su tierra en en los terminos e tierra confejiles...." ". Se trataba de diferenciar entre las tierras comunes, a las que se denomina realengos, y las tierras de propios del concejo, que habrían ido en aumento desde fines del siglo XV.

La preocupación que el concejo de Soria manifiesta a partir de 1502 por ampliar la extensión de sus bienes de propios resulta interesante. No es que la ciudad careciese de propios, los tenía aunque no los llamase de ese modo, se trataba de los términos concejiles que entregaba a los concejos de la tierra para pastos y cultivo, a cambio de una cantidad a modo de renta '2. En 1502 una denuncia de los procuradores de la tierra deja patente que la ciudad arrendaba terminos comunes y términos de lugares despoblados, que eran pastos comunes de la ciudad y de su tierra ${ }^{33}$. Tales arriendos serían recaudados por el mayordomo y a estos ingresos había que añadir la parte que se le asignaba al concejo de los montazgos o caloñas impuestas a los infractores. ¿Cuál pudo haber sido la causa de ese interés que manifestaba la ciudad en ampliar los terrenos de propios?

El primer argumento a favor de la creación de propios lo dio la propia Universidad de la tierra de Soria: k... disiendo que los regidores desa dicha çibdad dan licençia para herbajar en los términos desa dicha çibdad a algunos ganados que son de fuera de su tierra, lo qual dis que fasen disiendo que esa dicha çibdad tiene pocos propios e que an menester mas quantias de mrs. para sus nesçesidades en lo qual dis que si asy pasase los dichos sus partes resçibirian mucho agravio». Proponen que, si los regidores dejan de dar licencia para hervajar a los ganados extranjeros, ellos «... estaban prestos de contribuir en las nesçesidades desa dicha cibdad fasta en la cantidad que fuese justow ". Ya en el mes de marzo de 1511 el corregidor había recibido la orden de S.A. de recopilar información sobre qué espacios de esa ciudad podían pasar a ser propios y en qué lugares; para ello se manda que cuenten con la ayuda de los procuradores de los sexmos y lugares de la tierra". De nuevo en octubre vuelven a insistir en la creación de propios y obtienen carta de S.A. a su favor ${ }^{\text {. }}$.

II AGS/RGS, VIII-1510, Madrid 13 agosto 1510.

32 AGS/RGS, IV-1503, Alcalá de Henares 22 abril 1503.

33 AGS/RGS, V-1502, Toledo 24 mayo 1502.

34 AGS/RGS, VII-1510, Madrid 14 de Julio 1510.

ss AGS/RGS, III-1511; Sevilla 27 marzo 1511.

36 AGS/RGS, X-1515, Madrid 26 de Octubre 1510. 
No sólo el concejo de los regidores de Soria solicitaba tierras para propios, también el común de la ciudad requería de S.S.A.A. la asignación de unos propios en su favor para poder así pagar los salarios de un letrado y de un procurador".

La respuesta al interrogante planteado sobre la necesidad de ampliar los propios, por parte del concejo, nos lleva de nuevo al problema de la presencia del ganado lanar en la tierra de Soria, amparado por el Concejo de la Mesta. De hecho en agosto de 1510 el concejo de Soria responde a una reclamación del Concejo de la Mesta donde agravios en abrevaderos y cañadas. El concejo de Soria se quejaba de las grandes multas que les ponían sus alcaldes por cultivar unos propios, que podrían valer hasta $17.000 \mathrm{mrs}$. anuales, a razón de un real, por lo que araban dos pares de bueyes en un día ${ }^{38}$. Defienden la existencia de los propios porque no afectaban ni a los abrevaderos ni a las cañadas y solicitaba que los propios fuesen protegidos, porque en ello iba la conservación de la población en estas tierras y su contribución a la hacienda regia".

Los alcaldes de la Mesta se habían convertido en los cancerberos de las tierras concejiles y de sus derechos en ellas, que eran equiparados a los de los vecinos para usar los términos comunes. Tal como dice el documento, el espacio ganadero es toda la tierra de la ciudad de Soria: «... desta çíbdad syendo como es toda ella cañada». Se comprende la preocupación del concejo de Soria, que veía con temor esa actitud y las consecuencias que podía tener para sus ingresos concejiles. Si las tierras de propios no se lograban mantener con el argumento de la necesidad de pastos, la hacienda concejil se vería amenazada y los vecinos de la tierra estarían poco dispuestos a compensar esas deficiencias con sus contribuciones.

\section{La defensa de las tierras de baldios}

La ocupación ilegal de términos en el concejo de Soria fue haciéndose más alarmante a partir de la segunda mitad del siglo XV, debido al crecimiento económico y a la inestabilidad política. La abundancia de tierras baldías y su particular sistema de explotación, amparado en el fuero, sirvió de tentación para los vecinos y, en particular, para los mismo miembros de la oligarquía urbana, interesados en ampliar sus bienes patrimoniales.

Las reclamaciones del concejo a la instancia del poder monárquico para que esas tierras les fueran devueltas tuvieron que ser frecuentes. Ya en 1475, los reyes mandaban a las justicias de Soria que proveyesen en sustituir al concejo todos los lugares y términos que fuesen de la ciudad y estuviesen ocupados. En 1480 la Universidad de la tierra de Soria presenta una relación de lugares ocupados y de

37 AGS/RGS, IX-1500, Valladolid 11 septiembre 1500.

38 AGS/RGS, VIII-1510, Soria 14 agosto 1510.

99 Ibid.: «... si un labrador tiene arrendado de la dicha çibdad lo que haran dos pares de bueyes en un dia por un real de renta llevanle şinco mil mrs. de pena... no syendo ningunas destas tierras que ansy se labran en perjuizio del abravadero ni cañada mas metidas en los montes e arrendadas a vezinos de las sierras desta çibdad, a cuya cabsa algunos logares estan poblados que no lo estarian, e por su vezindad los montes e pinares estan guardados y las alcavalas desta universidad ayudadas e mucha parte destos vuestros reynos proveydos de madera, lo que no podría ser ni darse recabdo syn vezindad en la guarda de los montes.... 
quienes los mantienen bajo su poder (ver cuadro). La lista se amplía en 1514, a petición del concejo de la ciudad ${ }^{\circ}$.

La relación de ocupantes incluye vecinos de la ciudad y de la tierra, cuyos nombres recuerdan a familias de regidores y a miembros de los linajes, alcaides y personajes de relevancia en la vida del concejo. Resulta curioso como algunos de ellos han incorporado el topónimo del lugar que ocupan al patronímico, como Juan Díaz de Fuentcaliente o Ferrand Garçia Desparza (ver cuadro), buscando un arraigo necesario para la construcción de un linaje y una casa solar.

Las ocupaciones más denunciadas son las de "términos e prados e pastos e labranças e abrevaderos" y podríamos pensar que la reclamación busca adaptarse al enunciado que se había expuesto en las Cortes de Toledo ${ }^{61}$. Pero en ocasiones se añaden otras precisiones que prueban que la ocupación era más permanente de lo que cabría suponer, ya que se mencionan casas, palomares y tierras de labor (huertos y tierras de pan llevar). En otros casos se dice que lo ocupado son lugares derraigados, útiles para el apacentamiento del ganado.

En 1493 y 1497 se reclama de nuevo la desocupación de dehesas, prados, pastos y abrevaderos y se señala la ineficacia de las últimas decisiones, porque los términos, después de restituidos habían sido vueltos a ocupar ${ }^{62}$. En 1508 el concejo solicita la intervención de un juez de términos para que averigüe que tierras, montes, prados, aguas y abrevaderos tienen ocupados ilegalmente a ese concejo ${ }^{63}$. Tampoco debió de ser definitiva esta intervención, porque en 1514 el problema permanecía planteado y para él se pedía una solución ${ }^{64}$.

A pesar de la escasa documentación sobre las ocupaciones, el análisis y la localización de los datos obtenidos ha permitido hacer algunas valoraciones. Así, se puede afirmar que los ocupantes de términos son en su mayoría vecinos de la ciudad y de la tierra. Sólo Diego de Mendoza y D. Carlos de Arellano, miembros de la alta nobleza, pueden ser considerados foráneos. La localización de sus ocupaciones revela que tienen lugar en las fronteras de sus territorios (Alparrache y Noviercas) y el objetivo era ampliar sus dominios. Durante el señorío de doña Isabel, esposa de Juan II, sobre Soria, se puso freno a las usurpaciones de extraños, al promulgar una disposición en la que se facultaba a los vecinos para prender a los extranjeros que encontrasen en los montes de la ciudad y de su tierra sacando leña ${ }^{\text {ss. }}$.

Las restantes usurpaciones se reparten en el territorio de Soria de una forma peculiar, ya que tienden a concentrarse en unos ámbitos concretos (ver mapa): una buena parte se sitúan a orillas o en las proximidades de los ríos Duero, Razón, Tera, Merdancho y Riotuerto. Otras dos grandes bolsas se sitúan en dos zonas próximas a

60 AGS/RGS, II-1475, fol. 124, Segovia 8 febrero 1475; Ibid. III- 1480, fol. 225; Toledo 23 marzo 1480; AGS/C-C (Pueblos), Leg. 20, Soria 29 noviembre 1514.

61 «CORTES de los antiguos reinos de León y de Castillaw, Madrid, 1882, IV, 82, pp. 154-57.

62 AGS/RGS, VIII-1497, Medina del Campo 27 agosto 1497.

63 AGS/RGS, VII-1508, Burgos 6 julio 1508. En esta ocasión el juez de términos Cristóbal Dávila acude con poderes para restituir lo ocupado.

64 AGS/RGS, C-C. (Pueblos) Leg. 20. 1514. El argumento legal es la ley de Cortes de Toledo de 1480, que se dice puede ser aplicada ya que algunas de las ocupaciones se hicieron hace más de cuarenta años.

65 AGS/RGS, XII-1500, Valladolid 7 diciembre 1500. 
la ciudad de Soria, dejando a la ciudad en una posición central, de tal manera que una de ellas quedaría en el cuadrante nordeste y la otra en sudoccidental. Esta última sería el espacio simétrico de la dehesa del Valonsadero y con unas características de terreno muy similares. Por último cabe señalar zonas en las que se desarrollaba una actividad agrícola destacada, como las tierras de Blasco de Morales, Francisco de Cuéllar y Ferrand Desparza, que se encuentran más dispersas.

La explicación de esta particular disposición de las tierras ocupadas lleva a reconocer que pretendían hacerse con la posesión de tierras de pasto permanente. La proximidad de los ríos o bien una amplia extensión de tierras podían garantizar pastos para el ganado lanar. De esta forma la oligarquía urbana trataba de construirse un patrimonio de explotación ganadera en la tierra del concejo de Soria, próxima a la ciudad. Los primeros pasos se habrían dado en las décadas de los sesenta y setenta del siglo XV y el proceso seguía en marcha a la altura de 1514. Eran pues dominios de reciente creación, que aseguraban pastos a los ganados trashumantes. La oligarquía urbana había apostado fuerte por esta forma de ganadería y no quería desaprovechar la ventaja de vivir en una zona de tránsito ganadero hacia extremos. La creación de sus propias cabañas de ganado lanar iría al hilo de estas ocupaciones de términos, que les aseguraban los pastos de verano.

Otro de los argumentos que apoya la utilización ganadera de estas ocupaciones es, por una parte, que se incluyen términos derraygados, que eran despoblados, y por otra, el elevado número de lugares que se mencionan y que en la actualidad son despoblados. Es sabido que esta actividad ganadera no requiere asentamientos permanentes de población, ni estimula la vida agraria. De ahí su despoblamiento posterior.

De las fortunas mencionadas en la reclamación (ver cuadro) cabe destacar: la acumulación de términos en algunos de los personajes o en una familia, y su localización próxima en un territorio. Así los Barrionuevo los tienen a la orilla del Duero, al sur de Soria, y Pedro de Barrionuevo trataba de asentarse en Duruelo ${ }^{66}$. Los de Juan de Torres en el gran espacio hoy casi despoblado, al sur del Valonsadero, y los de Juan de Morales en el curso alto del Duero y en las proximidades de Soria (ver mapa).

El modo de introducirse los usurpadores en el término de un concejo de la tierra no puede ser precisado, pero cabe imaginar como sería en la mayor parte de los casos. Se comenzaba por la adquisición de casa y alguna heredad en el lugar, a fin de acceder a los pastos de los términos concejiles. A partir de aquí la capacidad de dominio económico, social y político se pondría a prueba y trataría por todos los medios de atraer y neutralizar a los vecinos. No debía resultar difícil a un caballero de Soria ganarse la aprobación y confianza de los vecinos. Por lo menos así lo expresa el procurador de Pedro de Barrionuevo al definirle como:

«... hombre fijodalgo de buenas costumbres e muy paçifico e tiene fasienda e casa sobre si y es mançipado ...no es revoltoso, ni poderoso, ni tan rico que mas no

66 AGS/C.-C. (Pueblos) Leg. 3, Soria 13 abril 1509. Reclamación contra el rechazo del concejo de Duruelo a admitir a Pedro de Barrionuevo como vecino, al haber comprado una heredad en ese lugar. 
querria ser, no a fecho, ni faze ni espera facer mala vezindad al dicho conçejo de Duruelon ${ }^{67}$.

De Pedro de Barrionuevo nos desvela sus pretensiones acerca de los términos del concejo de Duruelo y puede servir de ejemplo para comprender la actitud de estos usurpadores de tierras concejiles. Dice así:

«...porque aunque sus ganados meta en sus términos es encima de las sierras e por espaçio de tres meses o quatro por que lo demas estan en extremos y ally en las dichas syerras ninguna nesçesidad tienen los bueyes ni ganados del dicho lugar... quanto mas que ay termino e pasto en las syerras del dicho lugar para treynta mill cabeças de ganado poco mas o menos, syn que abaxen a lo llano ni a las dehesas ni prados, ni a los conçejiles del dicho lugar quanto mas que en todo el dicho lugar no ay mill e quinientas ovejas groseras e otras tantas cabras..."

El texto revela el estudio económico, social y jurídico que el reclamante había hecho y la habilidad con que sabía plantear sus argumentos, que coinciden en la utilización prioritaria de las tierras ocupadas para asentar a ganados trashumantes, tal y como se ha visto.

\section{LOS BALDÍOS Y EL GANADO TRASHUMANTE EN LA TIERRA DE SORIA}

\section{La situación económica a fines del siglo $X V$}

La situación de la economía soriana en la segunda mitad del siglo XV debe entenderse como el resultado de un efecto de arrastre provocado por el crecimiento que conoció la Corona de Castilla, cuya situación económica favorable sirvió de tirón para Soria. Pero su economía agropecuaria estaba construida sobre una peculiar forma de organización socioeconómica, que mostró su fragilidad al empuje de nuevos elementos. A resultas de esos contactos, la producción soriana se volcó en la ganadería y en la comercialización de madera. Estos serán recursos básicos y, en torno a la riqueza que de ellos se obtenía, se reorganizó la vida socioeconómica.

\section{La madera}

En la tierra de Soria se producía madera desde hacía siglos, pero la demanda de este producto se disparó en este período. La preservación de los montes y la venta de la madera eran circunstancias comunes de los concejos del noroeste de Soria, que se asociaron en la Hermandad de Pinares formada por: Palacios, Belviertre, Canilosa, Quintanar, Riomiel, Duruelo y Covaleda. En 1482 les acusan de formar una liga y monopolio para su defensa y de que no vendían madera a algunos concejos, argumentos que niegan las partes contrarias ${ }^{68}$.

El concejo de Duruelo es uno de los más interesados en desarrollar esa actividad en Soria, y llegaba a asegurar que si los guardas de la ciudad perturbaran a sus vecinos y les quitaran los pinos, robles y hayas, tal actitud iría en grave perjuicio del

67 Ibid. fol. $1 \mathrm{r}$.

68 AGS/C.R., Leg. 60-5 (s.f.), Valladolid 23 julio 1482. 
concejo de Soria e incluso los lugares de la dicha tierra se despoblarían ${ }^{69}$. Alegaban que:

"Otrosy sabra V.A. que los vesinos de los lugares de la dicha tierra e los dichos mis partes e yo hemos estado en posesión del dicho tyempo aca de faser madera en los dichos montes o terminos comunes e concegiles, por que ay mucha abundançia dellos e como la tyerra es esterile e mucha parte della ynabitable la mayor parte de los vesinos del dicho logar e casi todos se mantienen e non tyenen otro ofiçio salvo faser madera».

A partir de 1504 el concejo de Duruelo y la Universidad de la tierra de Soria se quejan de que el concejo, justicia y regidores les perturban en su tareas de coger madera, actividad que era vital para su subsistencia ${ }^{70}$.

Aunque las razones del concejo para impedir la tala de árboles tienen planteamiento de defensa de los baldíos, sabemos que en el fondo de las mismas planea una abierta oposición entre dos formas opuestas de explotar el bosque: la explotación maderera y la ganadera. Las razones de su oposición radican en el carácter predominante que pretenden ambas, al ser actividades que reportaban beneficios asegurados. Pero tampoco se puede olvidar que el concejo y regidores de Soria habían optado por la explotación de la ganadería trashumante y eso exigía pastos y amparo al movimiento de los ganados. En respuesta los procuradores de la tierra defendían la necesidad de cortar madera para su uso o para vender a otros, según lo señalaban los fueros, y si se lo impidieran la tierra se despoblaría.

\section{La ganadería}

La ganadería fue una actividad desarrollada desde siempre en Soria, pero durante siglos se había combinado con la agricultura, en una organización del espacio que la hacía complementaria (monte hueco, derrota de mieses, cultivos de año y vez, dehesas colectivas). Los animales que se criaban entonces eran predominantemente cerdos, cabras, ovejas y bueyes. Su número y movimientos se acoplaban a un sistema de vida agropecuario, sin grandes desplazamientos.

Desde mediados del siglo XV la ganadería trashumante comienza a aparecer en tierra de Soria con mayor frecuencia, amparada en los privilegios y exenciones concedidos por la monarquía. Su prolongada presencia trastornó la vida económica y social del concejo. En primer lugar rompió el antiguo equilibrio entre agricultura y ganadería. Además se benefició de los extensos términos concejiles y de la protección que el fuero otorgaba a los ganados en movimiento en el interior de la tierra. Consiguió romper el equilibrio interno del grupo oligárquico de los caballeros constituido en linajes. De esta manera la Mesta y los ganados mesteños se habían introducido en Soria en un plazo relativamente breve de tiempo y se encontraban allí firmemente asentados.

Aunque la Mesta y los miembros de la oligarquía urbana estuvieran conectados, manteniendo intereses comunes, las relaciones entre ambos no fueron fáciles. Por

69 AGS/C.R., Leg. 72-16, Medina del Campo 14 de Octubre 1504.

70 AGS/RGS, X-1504, Medina del Campo 17 octubre 1504. 
una parte, los justicias de la Mesta se volcaron en la defensa de sus derechos de paso y el uso de los abrevaderos, y de ahí surgieron diversos enfrentamientos con los regidores de Soria y los vecinos de su tierra".

La movilidad, que había caracterizado a la ganadería y a la agricultura sorianas, perturbaba al Honrado Concejo de la Mesta, decidido a fijar los pasos y las zonas de pasto que tenían asignadas por el uso y el amparo de los privilegios reales ${ }^{12}$. Los vecinos de la tierra fueron los mas afectados, debido a que su agricultura se vio pospuesta para algunas zonas, salvo graves penas. Resulta interesante el acuerdo logrado entre la Mesta y el concejo de Soria para perseguir el cultivo y roza de las tierras, actividad que se había practicado sin trabas en los términos concejiles hasta entonces ${ }^{13}$.

Una de las consecuencias más llamativas del afianzamiento del Concejo de la Mesta en Soria fue la facilidad con que gentes de fuera de la tierra, poseedoras de rebaños, se beneficiaron de los pasos, pastos y abrevaderos del concejo. Ante esto, protestaron enérgicamente los dueños de ganado del concejo, que se sentían agraviados por el trato preferente que recibían los ganados de los miembros de concejo (regidores y oficiales) y los de muchos hombres principales y alcaides de algunos lugares, ya que los guardas no les imponen penas, porque hacían lo que los regidores les mandaban ". Esa diferencia de trato revela la afinidad del grupo dominante, que hacía prevalecer la jerarquía social por encima del amparo equitativo de las normas.

\section{LAS TIERRAS DE BALDÍO Y EL PODER MONÁRQUICO}

La participación de la monarquía de los Reyes Católicos en la preservación de las tierras de baldío tuvo efectos contradictorios en el concejo de Soria. La acción del poder monárquico se ejercía por la aprobación de leyes con vigencia para todo el reino, por normas y ordenanzas dadas al concejo y por la atención de apelaciones presentadas ante su audiencia. La presencia del corregidor en la ciudad reforzaba la capacidad y el poder del monarca en Soria.

El concejo y tierra de Soria tuvo que enfrentarse, en el siglo XV, a la adaptación de su economía y a la consecuente organización del espacio. Estos cambios rompieron una precaria armonía entre caballeros y vecinos en el uso de la tierra. De esa ruptura se iban a derivar futuras tensiones entre una nobleza urbana dinámica, dispuesta a acabar con viejas ataduras, para construirse importantes patrimonios

7 AHN/MESTA Caja 193 (11). En 1514 se recogen averiguaciones y sentencias sobre términos ocupados por caballeros y concejos de Soria, dadas en favor del Concejo de la Mesta por el licenciado Chinchilla.

72 AGS/C.-C. (Pueblos), Leg. 20, Madrid 6 febrero 1514.

73 AGS/C.-C. (Pueblos), Leg. 20, Soria 20 diciembre 1508. Sentencia judicial sobre la reclamación de un paso presentado por el concejo de Soria, ante la ocupación de términos hecha por los herederos de Valdecabrejas.

74 AGS/RGS, VIII-1 S10, Madrid 13 de agosto 1510: «El conçejo justiçia e regidores desa dicha çibdad e su tierra a muchos hombres prinçipales e alcaydes de algunos logares... so color de alguna tierra que tengan en esa dicha çibdad ni en su tierra, syn que los tales personas moren en esa dicha çibdad ni en su tierra, lo cual dis que fasen a cabsa de herbajar sus ganados en los pastos desa dicha çibdad, e por gosar de los montes dellaw. 
ganaderos, y los vecinos de la tierra, que desde tiempo inmemorial habían usado las tierras de baldío que ahora se ambicionaban para pastos.

La monarquía en esta situación actuó con ambigüedad ya que, por una parte, atendía las reclamaciones de los concejos y vecinos de la ciudad y de su tierra, pero no lograba frenar el avance de las usurpaciones que éstos practicaban en su territorio. Por otro lado, en 1497, a instancia de la monarquía ", el concejo reunido en la iglesia de San Gil de Soria aprobó una normativa que hubiese sido definitiva en el conflicto antes mencionado. En ella no sólo se corregían y ampliaban las penas por no cuidar y preservar el monte ${ }^{76}$, sino que se amparaba abiertamente su utilización preferente para pastos de ganado "y se penalizaban las rozas y los cultivos, al igual que la corta de madera ${ }^{78}$.

No tenemos noticias de que esas ordenanzas fuesen aprobadas por los monarcas, a pesar de la insistencia del concejo de Soria para conseguir la ratificación. De hecho las tierras concejiles se siguieron labrando, lo mismo que se mantuvo la corta de madera. Su aprobación hubiese sido el apoyo perfecto que la oligarquía ganadera necesitaba. Pero tampoco actuaron a favor de los vecinos de la tierra cuando reclamaban el respeto a la norma del fuero. De todo esto cabe deducir que los monarcas no quisieron intervenir en un proceso de transformación de la sociedad y de la economía sorianas, que prometía ser definitivo para el futuro y que presentaba un pronóstico claramente favorable a la oligarłquía ganadera. Esa discutible neutralidad se mantuvo a pesar de que de por medio estaba en juego el futuro de las tierras de realengo: los baldíos.

\section{CONCLUSIÓN}

A lo largo de estas líneas se ha ido observando la íntima relación que existía entre el espacio y la organización económica y social de las personas que lo habitaban. En el caso de Soria esa conexión evolucionó a ritmo lento hasta mediados del siglo XV, cuando se iniciaría un ritmo rápido de transformación. Detrás de estos cambios estaba el desarrollo económico de la Corona de Castilla, la movilidad social y los cambios políticos que la acompañaron. El análisis histórico se ha realizado a partir del estudio de las tierras de baldío, que guardaban un potencial económico importante y deseado por distintos grupos sociales.

7s AGS/RGS, IV-1497, fol. 131, Burgos 15 abril 1497.

76 AGS/C.-C. (Pueblos) Leg. 20, Soria 30 junio 1497: «Ordenanzas que se fiçieron en la çibdad de Soria sobre las penas de los montes e serrados por el corregidor e regidores e procuradores de ella e de su tierrax.

77 Ibid. fol. 7v: «Otrosy ordenaron que en los que tienen tomados los terminos reales de la çibdad e los exidos della çerrandolos e asymismo arando las majadas, e los exidos e otras entradas e salidas que son muy nesçesarias para los ganados, estan asymismo en lo realengo, que todos lo dexen para que sea pasto común para la dicha çibdad e su tierra segund que los otros exidos e realiengos son e estos lo fueron e qualquier que de aqui adelante araren en los dichos exidos e realiengos que le prenden por cada ves que le fallaren arando o çerrando por sesenta mrs. e le puedan tomar el pan e segar la yerva syn pena ninguna....

78 Ibid., fol. 8r: a... Otrosy por que los naturales de la tierra de la dicha çibdad furtan e talan mucho los montes para llevar a vender leña fuera de la jerediçion e para lo dar a sus amigos o parientes e sobrello se hasen muchas encobiertas e fraudes por ser la pena de la ley muy pequeña, que qualquiera que sacare la dicha leña le lleven de pena qualquier que le tomare veynte mrs. de cada carga, e asymismo aya la leña perdida e de cada carreta sesenta mrs. de la leña perdidaw. 
Sobre el uso de los baldíos surgen opciones diversas, pero las diferencias se reducen, en último término, a dos propuestas: una primera, apoyada por los concejos de la Hermandad de Pinares, que defendía la preservación de los baldíos según el fuero y la costumbre habían marcado, porque era compatible con una explotación maderera, que nada tenía que ver con la practicada en el período anterior; la otra postura buscaba una ruptura con el fuero de 1256 y con la defensa de los baldíos como tierras temporales de labor, a fin de adaptar su aprovechamiento a la explotación del ganado trashumante.

Desde ambas perspectivas se estaba pretendiendo un mismo objetivo: la plena integración de Soria y su tierra en la vida económica de la Corona. Pero el propósito exigía cambios demasiado bruscos que se habrían de realizar en poco tiempo. Las consecuencias las pagó con creces la población pechera de la ciudad y de la tierra cuyo destino tuvo que ser incierto durante mucho tiempo. Ellos tuvieron que afrontar los cambios, amenazados e indefensos, y como habrían tenido que buscar la protección y posiblemente la dependencia, en unas condiciones de vida nuevas, ya fuera integrándose en un concejo rural o entrando en la dependencia de los nuevos señores ganaderos.

MARÍA ASENJO GONZÁLEZ Universidad Complutense, Madrid. 
Usurpaciones de términos denunciadas en la tierra de Soria

\begin{tabular}{|c|c|c|c|c|}
\hline Año & Loc. & Lugar & Nombre & Bienes \\
\hline 1480 & & Aldehuela & Diego de Vera & \\
\hline 1480 & desp. ${ }^{\prime}$ & Ontanilla & Juan de Torres & \\
\hline 1480 & desp. & Sinova & Juan de Torres & \\
\hline 1480 & & Fuentetecha & Juan de Torres & \\
\hline $\begin{array}{l}1480 \\
1480\end{array}$ & $\begin{array}{l}\text { desp. } \\
\text { desp. }\end{array}$ & Ribamilanos & Juan de Torres & \\
\hline & & valcaballar & Nicolás de Sant Clemente & \\
\hline 1480 & desp. & La Sequilla & Alcaide de Gómara & \\
\hline 1480 & desp. & Ribarroya & Alcaide de Gómara & \\
\hline 1480 & desp. & $\begin{array}{l}\text { Villarejo y su tér- } \\
\text { mino }\end{array}$ & $\begin{array}{l}\text { La mujer de Diego Fernán- } \\
\text { dez }\end{array}$ & \\
\hline $\begin{array}{l}1480 \\
1480\end{array}$ & desp. & $\begin{array}{l}\text { Valverde } \\
\text { Camparañón }\end{array}$ & $\begin{array}{l}\text { Lope de Sant Clemente } \\
\text { Lope de Sant Clemente }\end{array}$ & \\
\hline 1480 & $s / 1^{2}$ & Alparrache y su & & \\
\hline & & término & Diego de Mendoza & \\
\hline $\begin{array}{l}1480 \\
1480\end{array}$ & $\begin{array}{l}\text { desp. } \\
\text { desp. }\end{array}$ & $\begin{array}{l}\text { Olmedillos } \\
\text { Malluembre }\end{array}$ & $\begin{array}{l}\text { Rodrigo de Morales } \\
\text { El Dottor }\end{array}$ & \\
\hline 1480 & $s / 1$ & Cobaledilla & $\begin{array}{l}\text { El Alcaide Jorge de Beteta y } \\
\text { su hijo }\end{array}$ & \\
\hline 1480 & desp. & La Pica & $\begin{array}{l}\text { El Alcaide Jorge de Beteta y } \\
\text { su hijo }\end{array}$ & \\
\hline 1480 & desp. & Compratoçes & $\begin{array}{l}\text { Alcaide Jorge de Beteta y su } \\
\text { hijo }\end{array}$ & \\
\hline 1480 & desp. & Blasco Nuño & $\begin{array}{l}\text { La mujer del Alcaide Barrio- } \\
\text { nuevo }\end{array}$ & \\
\hline 1480 & & $\begin{array}{l}\text { Portillo y su tér- } \\
\text { mino }\end{array}$ & Ferránd de Barrionuevo & \\
\hline 1480 & & Torretartajo & Juan de Barrionuevo & \\
\hline 1514 & desp. & Las Luengas & Juan de Morales (regidor) & \\
\hline 1514 & & Olmedillos & Juan de Morales & \\
\hline 1514 & $s / 1$ & Mazarrones & Juan de Morales & \\
\hline 1514 & $s / 1$ & Almunharien & Juan de Morales & $\begin{array}{l}*, 10 \text { yuntas de } \\
\text { heredad }\end{array}$ \\
\hline 1514 & $s / 1$ & Termoso & Juan de Morales & \\
\hline 1514 & desp. & Escarabajosa & Juan de Morales & \\
\hline 1514 & $s / 1$ & Castellanos(?) & Catalina de Morales, Juan & \\
\hline & & & $\begin{array}{l}\text { Morales, Juan de Ortega, } \\
\text { Diego de la Serna, Pedro de }\end{array}$ & \\
\hline & & & la Serna & \\
\hline 1514 & $s / 1$ & Aldehuela & Juan de Vera & $*$ \\
\hline 1514 & & Aldealseñor & Iñigo de Salcedo & * \\
\hline 1514 & $s / 1$ & Çerujales & Iñigo de Salcedo & * \\
\hline 1514 & desp. & Garraejo & Gonzalo de Santa Cruz e & $*$ \\
\hline & & & $\begin{array}{l}\text { Iñigo de Santa Cruz, su her- } \\
\text { mano }\end{array}$ & \\
\hline
\end{tabular}




\begin{tabular}{|c|c|c|c|c|}
\hline Año & Loc. & Lugar & Nombre & Bienes \\
\hline 1514 & $1 / d^{3}$ & Villarejos & $\begin{array}{l}\text { Juan de Ortega, Diego de la } \\
\text { Serna, Pedro de la Serna, La } \\
\text { mujer de Valpuesta y la de } \\
\text { Diego de Vera }\end{array}$ & - \\
\hline 1514 & $1 / d$ & Caravacholes & Ibidem & - \\
\hline 1514 & $s / l$ & Quiñones & Antonio de Morales & • \\
\hline 1514 & $\mathrm{~s} / \mathrm{l}$ & $\begin{array}{l}\text { Ventosa del Cam- } \\
\text { po }\end{array}$ & Antonio de Morales & - \\
\hline 1514 & & Riotuerto & Leonor de Castro & * \\
\hline 1514 & & $\begin{array}{l}\text { Torre de Naval- } \\
\text { cavallo }\end{array}$ & $\begin{array}{l}\text { Blasco de Medrano y D. }{ }^{.} \text {Ca- } \\
\text { talina, su mujer }\end{array}$ & - \\
\hline $\begin{array}{l}1514 \\
1514\end{array}$ & desp. & $\begin{array}{l}\text { Fuentcaliente } \\
\text { Fuentetoba }\end{array}$ & $\begin{array}{l}\text { Juan Diaz de Fuentcaliente } \\
\text { Blasco de Morales }\end{array}$ & $\begin{array}{l}20 \text { yugadas y } \\
\text { una cerrada }\end{array}$ \\
\hline $\begin{array}{l}1514 \\
1514\end{array}$ & $s / 1$ & $\begin{array}{l}\text { Los Vercoles } \\
\text { Alconava }\end{array}$ & $\begin{array}{l}\text { Blasco de Morales } \\
\text { Francisco de Cuéllar }\end{array}$ & $\begin{array}{l}10 \text { yugadas } \\
2 \text { yuntas, ca- } \\
\text { sas, un palo- } \\
\text { mar y pastos }\end{array}$ \\
\hline 1514 & $s / 1$ & Esparza & Ferrand Garçía Desparza & $\begin{array}{l}1 \text { yunta, casas } \\
\text { y solares }\end{array}$ \\
\hline
\end{tabular}

- Prados, pastos, labranzas y abrevaderos.

1 Despoblado actual

2 Sin localizar

3 Lugares derraygados

4 Conocido como Torreambroz 


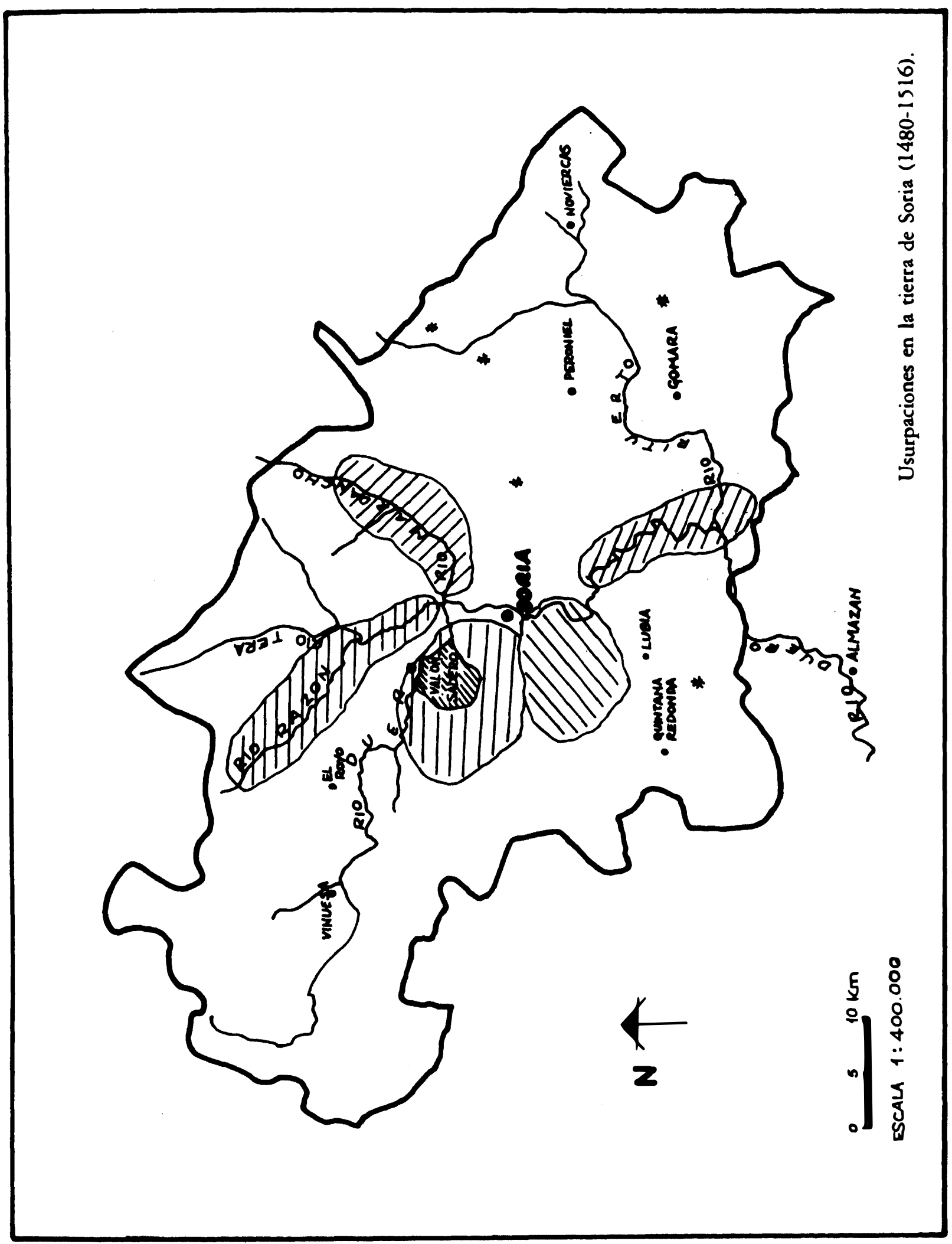

